\title{
Las concepciones centrales del liberalismo y del socialismo sobre la nación en Europa: 1850-1914*
}

\section{The central conceptions of the liberalism and socialism on the nation in Europe: 1850-1914}

SUMARIO

Introducción. I. La "nation buiding" en Francia y en Alemania: dos procesos, dos ideas. II. Problemas de la nación, nacionalidad y nacionalismo en la segunda mitad del siglo xIx: liberalismo y socialismo. A. El liberalismo: Lord Acton y Ernest Renan. B. El marxismo: Friedrich Engels y Karl Marx. iII. Dos reflexiones desde el liberalismo y el socialismo antes del fin del largo siglo xix: Friedrich Meinecke y Otto Bauer. A. Friedrick Meinecke y los procesos de conformación de la nación en los Estados nacionales modernos. B. Отто BAUER, el austromarxismo y el problema de las nacionalidades. Reflexiones finales.

\section{RESUMEN}

El artículo presenta desde la historia del pensamiento político las reflexiones centrales alrededor del tema de la nación en Europa de las dos corrientes de pensamiento más importantes de la segunda mitad de siglo XIX, el liberalismo y el socialismo. Desde mediados del siglo las cuestiones de la nación aparecieron para estas dos corrientes como un problema complejo y difícil. Dentro de su contexto político y a través de literatura secundaria, pero sobre todo del estudio de los textos de los mismos autores, se exponen,

* Recibido el 12 de octubre 2014, aprobado el 11 de febrero de 2015.

Para citar el artículo: M. L. QuiROga Riviere. Las concepciones centrales del liberalismo y del socialismo sobre la nación en Europa: 1850-1914. Revista Derecho del Estado n. . 34, Universidad Externado de Colombia, enero-junio de 2015, pp. 255-287. DOI: 10.18601/01229893.n34.12

** Socióloga de la Universidad Nacional con maestría y doctorado en Ciencia Política en el Otto-Suhr Institut de la Universidad Libre de Berlín. Docente-investigadora del Centro de Investigaciones y Proyectos Especiales (CIPE), Facultad de Finanzas, Gobierno y Relaciones Internacionales de la Universidad Externado de Colombia. Contacto: angela.quiroga@uexternado.edu.co 
desde el liberalismo, las reflexiones en su debate sobre la "nacionalidad" y el "principio de las nacionalidades" de Lord Acton, así como la concepción de nación de Renán; y, desde el socialismo, los aportes alrededor de "la cuestión nacional" en Polonia e Irlanda de MARX y Engels, para luego entrar a exponer las expresiones más decantadas y sistemáticas sobre el concepto de nación poco antes de la Primera Guerra Mundial del liberal conservador Friedrich MeInecke y del austromarxista OtTo BaUer. El texto muestra una problemática que lleva muchas décadas y unos presupuestos teóricos que, desarrollados en su tiempo, aún hoy juegan un papel en la teoría y la práctica alrededor del problema de la nación. Por esto, al final el artículo evalúa de manera sintética la resonancia de dicho legado.

PALABRAS CLAVE

Europa, liberalismo, marxismo, identidad nacional, historia contemporánea, ciencia política.

\section{ABSTRACT}

The article presents, from the history of the political thought the central reflections of the most important currents in the second part of the XIX century, liberalism and socialism, about the nation in Europe. From the middle of the century the questions about the nation were for these currents a complex and difficult problem. Inside its political context and using secondary literature but overall by studying the texts of the authors themselves the principle reflections of the liberalism will be exposed -the discussion about the nationality and the principle of the nationalities by Lord AcтоN and the question about what is (the meaning of) the nation asked by RenAN, and from the viewpoint of the socialism -the contributions about the national question in Poland and Ireland of MARX and Engels. The article develops than the most systematized reflections about the nation shortly before the First World War, of the liberal conservative Friedrich MeInecke and the Austromarxist Otto BAUER. The text shows the continuity of an old and difficult problem with theoretical assumptions that although developed in their time still continue playing an important role for the theory and practice around the question of the nation till today. Therefore the article ends showing synthetically the echo of this legacy.

KEY WORDS

Europe, liberalism, Marxism, national identity, contemporary history, political science. 
INTRODUCCIÓN

A pesar de que el siglo XxI está ante una realidad globalizada y ante el cuestionamiento del Estado nacional y el Estado-nación, sigue siendo una característica de nuestro mundo contemporáneo el lenguaje de la nación y los nacionalismos. Posterior a la caída del muro y con el nacimiento en Europa de veinte nuevos Estados nacionales articulados a un discurso de nación, muchos de ellos con conflictos cruentos como en los Balcanes, se vigorizó y amplió la discusión en el continente acerca de los orígenes y la naturaleza de las naciones y los nacionalismos, discusión que pareciera no mostrar visos de solución por los presupuestos que tienen las diferentes miradas teóricas que han tomado parte en el debate. Acertadamente se ha dicho que "la cuestión fundamental en el debate sobre el nacionalismo es el significado del término nación", precisamente por ser un término polisémico, de muy difícil definición pues, según el momento histórico o el lugar, asumirá diversos significados (SChwarzmantel, 1991, citado por Acosta SÁnchez, 1992, p. 98) ${ }^{1}$.

No es nuestro interés el introducirnos en los planteamientos sobre el concepto de nación que se desarrollaron como antecedentes en el siglo XVIII y que se sintetizaron en gran parte poco después de las revoluciones burguesas en Europa y América. Tampoco nos ocuparemos de los desarrollos posteriores a la Primera Guerra Mundial que hacia la década de los setenta mostraban ya un acumulado respetable. Textos como Nacionalismo y modernidad. Un estudio crítico de las teorías recientes sobre naciones y nacionalismo (SMITH, 2000) ofrecen una panorámica excelente de estas últimas propuestas teóricas sobre el tema de la nación y los nacionalismos en el siglo xx para el lector interesado en un primer acercamiento.

El presente artículo pretende-de forma sintética-desarrollar desde la historia del pensamiento político las reflexiones más relevantes del liberalismo y el socialismo sobre los problemas que cruzaron el tema de la nación moderna a partir de la mitad del siglo XIX y hasta el inicio de la Primera Guerra Mundial con la que termina el largo siglo $\mathrm{XIX}^{2}$. Creemos que es una importante tarea acercarse de nuevo a los autores clásicos que a partir de estas dos corrientes centrales del pensamiento en el siglo XIx, empiezan a ver la nación como un 'problema', como un fenómeno complejo y de difícil comprensión que de manera dramática cruzó la vida política europea a través de los movimientos nacionalistas, especialmente desde mediados del siglo XIX, culminando con la Primera Guerra Mundial, y sobre lo que se hacía imperioso reflexionar

1 Así, Acosta SÁnchez (1992) escribe que en inglés la palabra "nación" suele sustituir a la de Estado, y a lo largo de la historia ha llegado a tener seis significados en francés y hasta cinco en alemán.

2 Eric Hobsbawm desarrolla el largo siglo xix (1789-1914) en sus tres libros La Era de las Revoluciones, 1789-1848, La Era del Capital, 1848-1875 y La Era del imperio, 1875-1914. 
teóricamente. Estos autores (LORd Acton, ERnest RenAn, Friedrich ENGEls, Karl Marx, Friedrich Meinecke y Otto Bauer), que escribieron desde diferentes miradas -filosofía, historia, derecho-, dejaron unos legados que hacen parte hoy de las discusiones de la nación en Europa, ya sea alrededor de los movimientos nacionalistas o de los debates de la multiculturalidad y la ciudadanía.

Vamos a partir del problema de la nación desde los desarrollos de la nation-building en los dos casos representativos por excelencia en Europa, Francia y Alemania, porque allí nacen las dos controvertidas concepciones que hasta el día de hoy siguen jugando un papel importante no solo en la caracterización de los nacionalistas y sus nociones y proyectos de nación, sino también en alguno de los debates teóricos centrales contemporáneos ${ }^{3}$; para luego entrar a mirar los desarrollos teóricos alrededor de la nación a partir de autores de las tradiciones de pensamiento cardinales el el arco de tiempo que va de la mitad del siglo xix hasta antes de la Primera Guerra Mundial, a saber, el liberalismo y el socialismo.

El artículo no pretende entrar a hacer comparaciones entre las diferentes comprensiones teóricas de nación en el liberalismo y el socialismo, ni confrontar estas corrientes entre sí. El propósito es presentar la complejidad atisbada por los autores mismos en su contexto histórico y político. Quiere mostrar al lector interesado una problemática que lleva muchas décadas y unos presupuestos teóricos que, desarrollados en su tiempo, aún hoy juegan un papel en la teoría y la práctica alrededor del problema de la nación -y de los nacionalismos. Aunque intrínsicamente conectados ambos temas, el artículo se limita a la nación y no se ocupa del nacionalismo ni de los nacionalismos.

\section{LA “NATION-BUILDING" EN FRANCIA Y EN ALEMANIA:}

DOS PROCESOS, DOS IDEAS

La nación moderna como realidad aparece con la Revolución francesa, a finales del siglo XVIII y comienzos del XIX, y con esta se da inicio a un principio de legitimidad que, a pesar de las diversas acepciones - patria, pueblo,

3 Como bien lo sintetiza Sмiтн (2000), los debates se centran en tres grandes temas: la naturaleza y los orígenes de la nación y el nacionalismo; la antigüedad o modernidad de las naciones y los nacionalismos; la relación del pasado y el presente en la formación y el futuro de las naciones. Junto a estos tres grandes temas se han estructurado tres debates fundamentales: el debate alrededor de la concepción de nación de los organicistas frente a los voluntaristas (qué es la nación); el de los perennialistas frente a los modernistas (cuándo es la nación), y el de los socialconstruccionistas frente a los etnosimbólicos (cómo deviene la nación). A partir de estos tres debates se han decantado cuatro paradigmas teóricos que son los que marcan las diferencias en la concepción de la nación y el nacionalismo: el primordialista, el perennialista, el modernista y el etnosimbólico, cada uno con propuestas diferentes para entender el carácter, el papel y la formación de las naciones y los nacionalismos. 
nación-, cuestiona a fondo el principio de legitimidad que sustentaba al Ancien Régime y las monarquías absolutistas.

La idea de nación, sin embargo, tendrá dos orígenes en Europa, que darán pie a dos definiciones modernas dentro del mundo europeo y que obedecen a los diferentes desarrollos que se condensaron y sintetizaron, a finales del siglo XVIII y comienzos del XIX, en dos países centrales en el continente: la nation-building en Francia y en Alemania.

La doble acepción moderna de nación de la que usualmente se habla en los textos sobre el tema ${ }^{4}$ tiene así su origen en los procesos francés y alemán, y en sus contextos específicos camino a la construcción de una nación; el primero se nutre y tiene en su base las ideas de la Ilustración y la Revolución francesa dirigidas contra una monarquía que ya ha conseguido modelar un Estado altamente centralizado y cuyo representante en su momento toma cuerpo en LuIS XVI. El segundo proceso, pese a estar también bajo la influencia de la Ilustración y de la Revolución francesa, tiene lugar en el mundo alemán, caracterizado por una gran fragmentación política y que debe afrontar, poco después de 1789, la invasión napoleónica ${ }^{5}$.

Aunque se suele hacer una distinción entre la concepción de nación política en la Francia de 1789 y la concepción alemana del Volksgeist (espíritu del pueblo), hay que señalar que para ese momento ambas están inmersas en las ideas del siglo XVIII y en la lucha contra el antiguo régimen. Los dos desarrollos llevaron a lo que hoy se conoce entre los especialistas como la concepción dualista de la nación, la dicotomía entre "nación política" y "nación cultural", categorización que ha permitido, no sin controversias, sintetizar el proceso de la nation building en el continente europeo en dos tipos diferenciados, y comprender los distintos desarrollos y discursos de

4 Véase Blas Guerrero (1984 y 1994).

5 Es relevante señalar que ante la hegemonía cultural francesa, y luego con la invasión napoleónica, se desarrolla en Alemania el concepto de "cultura", en claro antagonismo al de "civilización", de ascendencia francesa e inglesa y que apunta a un proceso 'universal'. NORBERT Elias, en el tomo i de su libro Sobre el proceso de la civilización (1997), hace una hermosa e interesante disección sociológica de estos dos conceptos. En su análisis, contrapone en un primer momento la aristocracia cortesana alemana, representante del Ancien Régime y que desprecia lo alemán y habla francés, a una Intelligenzia alemana que pertenece a la pequeña burguesía y habla alemán; en su movimiento contra las estructuras calcificadas de su tiempo, la intelectualidad alemana realza la lengua y la cultura propia, diferenciándose así de una aristocracia que representa lo viejo y que es vista como un gran obstáculo, de una parte para el devenir de las nuevas ideas que trae el Siglo de la Luces en Alemania, y de otra, para el logro de la unidad nacional. Este concepto de "cultura", en oposición al de "civilización", asumirá después un carácter de diferenciación hacia Francia al momento de la invasión napoleónica. Con el devenir de los nacionalismos étnicos a finales del siglo XIX y del nacionalsocialismo en el XX, esta acepción tendrá en los grandes países europeos su más rabiosa y reaccionaria manifestación con el fascismo, el nacionalsocialismo y la terrible realidad del Holocausto. 
nación que enarbolaron los nacionalistas, y con ellos los nacionalismos del siglo XIX hasta hoy en día en Europa.

Aquellos países en que el Estado ${ }^{6}$ fue una realidad política contundente -las dinastías en Francia o Inglaterra- y que construirían durante un proceso de concentración de poder monarquías absolutistas ${ }^{7}$ base de las naciones políticas posteriores, dotadas de administraciones e instituciones centralizadas con unos territorios relativamente ya definidos y unas poblaciones relativamente estables en su interior, serán los lugares que mostrarán un desarrollo "clásico" de la nación política.

Por otra parte, la nación cultural tiene su fundamento en un grupo étnico con una cultura propia. De ahí el entusiasmo del Romanticismo alemán por lo propio, lo espontáneo, por el paisaje, por lo "natural". Soporte cultural de estas naciones serán elementos diversos, entre los cuales la lengua tendrá un rango importante como momento cultural y columna vertebral. En los territorios alemanes, la existencia de la lengua expresada a través del libro, factor decisivo que permitió el desarrollo de un lenguaje impreso que logra una literatura y una cultura escrita de gran envergadura, se convierte en el medio de comunicación de la Intelligenzia. Así, mientras Herder y GoEtHE escribían en Weimar (Ducado de Weimar), Kant lo hacía en Königsberg (Reino de Prusia) y Hölderlin en Homburg (Condado de Hessen-Darmstadt). La lengua daría cohesión a una "nación" cuya clase intelectual se encontraba diseminada a lo largo de un territorio fraccionado políticamente en una diversidad de Estados, reinos, principados, ducados, un territorio con múltiples soberanías. Condición de la nación cultural concebida por los teóricos alemanes de finales del siglo xviII fue, sin embargo, el logro de una organización política propia, es decir, el paso de una nación cultural a una nación política, lo que significaba llegar a conformar un Estado propio.

De esta manera la nación cultural, a diferencia de la política, no se orientaría por un Estado nacional histórico, y se desarrollaría antes que el Estado. Esta idea de nación corresponderá a una concepción que a partir de la segunda mitad del siglo xIX nutrirá a muchos de los movimientos nacionalistas de Europa central y oriental, y también a algunos occidentales, en la búsqueda por la independencia política a través de la consecución de un Estado propio. Hay que subrayar, empero, que aún hoy y desde siempre, en los diferentes

6 Recordemos que según un experto del devenir de los Estados en Europa como TiLly (1990), será solamente en el siglo XIX que los Estados nacionales se convertirán en la forma de organización política predominante en Europa. Antes y durante siglos coexistieron en este continente los "Estados-imperio", las "ciudades-Estado" y los "Estados nacionales". Tilly además nunca habla en sus textos del Estado nación sino del Estado nacional.

7 Los Estados absolutistas tienen variadas formas y tempos diversos de aparición. En el libro El Estado Absolutista de Perry ANDERson (1985) se lleva adelante un estudio pormenorizado de los diferentes desarrollos de las monarquías absolutistas tanto en Europa occidental como en Europa oriental. 
movimientos nacionalistas no se encuentran desarrollos "puros", sino una constante mezcla de elementos de la nación política y la cultural en un movimiento continuo de una a otra.

II. PROBLEMAS DE LA NACIÓN, NACIONALIDAD Y NACIONALISMO

EN LA SEGUNDA MITAD DEL SIGLO XIX: LIBERALISMO Y SOCIALISMO

El debate que se inicia en Europa a mediados del siglo XIX se da inmerso todavía en un contexto específico de lucha contra el Ancien Régime, lucha que iría hasta más o menos la segunda mitad de ese siglo con la derrota de las revoluciones del año 48; el nacionalismo -fuese basado en la concepción política de nación o en su acepción cultural- cuestionaba la legitimidad del antiguo orden (FusI, 2003).

Podemos afirmar que las dos corrientes de pensamiento más fuertes que dio el siglo XIX (liberalismo y comunismo/socialismo) se vieron obligadas a pensar y a indagar sobre las cuestiones de la nación o del nacionalismo: desde el liberalismo se expresa esto, y toma cuerpo en su debate sobre la "nacionalidad" y el "principio de las nacionalidades"; y desde el comunismo/ socialismo su expresión concreta serán los aportes alrededor de "la cuestión nacional". No obstante, estas primeras reflexiones no fueron teorías acabadas sino miradas referentes al problema ante todo político que suponía el asunto de las nacionalidades, la nación y los nacionalismos, que no significaron reflexiones acabadas sobre un cuestionamiento acerca del concepto mismo de nación. Vamos a adentrarnos en los textos y contextos de los autores más relevantes de la segunda mitad de siglo de estas dos corrientes, buscando presentar en contexto y resaltar sus planteamientos centrales alrededor del problema que nos ocupa.

\section{A. El liberalismo: Lord ACTON y ERNEST RENAN}

El liberalismo y el nacionalismo fueron de la mano en un primer momento: los principios de libertad y autonomía de la esfera individual se aplicaron a los pueblos cuyos principios habrían de respetarse de la misma manera que los de los individuos. Un sinnúmero de autores del liberalismo tendrá de esta forma una posición "nacionalista" -cercana tanto a la concepción de nación política como a la de nación cultural (Blas Guerrero, 1984). Dentro de ellos, John Stuart Mill; pero también Bentham, así como quien constituye el mejor ejemplo de la alianza entre nacionalismo y liberalismo: GiUsepPe MAZZINI ${ }^{8}$ (1805-1872), protagonista de la unificación italiana, que en algún momento dirá: "The people is penetrated with only one idea, that of

8 De él sería la conocidísima frase: "Hemos creado a Italia, ahora tenemos que crear a los italianos". 
unity and nationality [...]. There is no international question as to forms of government but only a national question" (citado por Acton, 1955, p. 157).

Dos textos dentro de la corriente liberal quedarán como clásicos del siglo XIX y aportes centrales hasta el día de hoy sobre el tema': un ensayo de Lord ACTOn y la conferencia dictada en la Sorbona, París, el 11 de marzo de 1882, por ERnest Renan. Fueron ellos quienes dentro del liberalismo se ocuparon de manera más específica sobre el tema.

El primero se titula Nationality, y fue escrito por Lord AстоN a la edad de 25 años y publicado en 1862. Su reflexión gira alrededor del "principio de nacionalidad" y toca desde allí los problemas de la nación. El escrito comienza por bosquejar el devenir histórico de la nacionalidad y con ello de "lo nacional" como principio determinante en la historia europea, sobre todo a partir de la tercera partición de Polonia en 1795 entre Rusia, Austria y Prusia, y, después de 1813, de todo el movimiento que se expresó en Irlanda, en la revolución en Grecia, Bélgica y Polonia, movimiento que se articuló en oposición a la invasión napoleónica y alrededor de los valores de la libertad, la religión y la nacionalidad. ACTON diferencia dos puntos de vista sobre la nacionalidad correspondientes a Inglaterra y a Francia, diferencia que FusI (2006) interpretará como "la naturaleza contradictoria del nacionalismo" percibida por AстоN. Esta naturaleza contradictoria oscilaba "entre dos ideas que a él se le antojaban opuestas e irreconciliables: entre la teoría política de la libertad y el principio de la unidad nacional" (Fusi, 2006) ${ }^{10}$.

Estos dos puntos de vista acerca de la nacionalidad se caracterizarán, según Acton, de diferente manera. De una parte, una concepción en donde los derechos colectivos, la nación, la nacionalidad y la etnicidad serían los determinantes en la visión de comunidad nacional -el principio de la unidad nacional-, mientras que la otra idea tendría en sus cimientos una teoría política de la libertad con base en las libertades civiles, el individuo y el ciudadano, y el pluralismo.

These two views of nationality, corresponding to the French and to the English systems, are connected in name only, and are in reality the opposite extremes of political thought. In one case, nationality is founded on the perpetual supremacy

9 En el debate de la nacionalidad participó también John Stuart Mill quien, sin embargo, dejó solo referencias cortas sobre el tema. Debemos advertir que ERIC HobSBAwm (1990), en su libro Nations and Nationalism since 1780, considera a John StUART Mill como el autor que escribió el mejor trabajo del liberalismo sobre la nacionalidad. En la introducción leemos que el liberalismo del periodo clásico del siglo XIX escribió poco sobre el tema y que "the best work produced at that time was actually very brief, like John STUART MILL's passages on the subject in his 'Considerations on Representative Government' and ERNEST RENAN's famous lectures 'What is a nation?"' (HoBsBawm, 1990, p. 2).

10 Disponible en: [http://www.ortegaygasset.edu/fog/ver/316/circunstancia/ano-iii--numero-9---enero-2006/ensayos/el-nacionalismo-en-el-siglo-xx]. 
of the collective will, of which the unity of the nation is the necessary condition, to which every other influence must defer, and against which no obligation enjoys authority, and all resistance is tyrannical. The nation is here an ideal unit founded on the race, in defiance of the modifying action of external causes, of tradition, and of existing rights. It overrules the rights and whishes of the inhabitants, absorbing their divergent interests in a fictitious unity; sacrifices their several inclinations and duties to the higher claim of nationality, and crushes all natural rights and all established liberties for the purpose or vindicating itself. [...] Connected with this theory in nothing except in the common enmity of the absolute state is the theory which represents nationality as an essential but not a supreme element in determining the forms of the State. It is distinguished from the other, because it tends to diversity and not to uniformity, to harmony and not to unit. While the theory of unity makes the nation a source of despotism and revolution, the theory of liberty regards it as the bulwark of self-government and the foremost limit to the excessive power of the State (AстоN, 1955, pp. 158, 159).

En este ensayo el liberalismo de ACTоN aparece en clara contraposición al nacionalismo y al derecho de las nacionalidades, y ello antes que en RENAN en su célebre conferencia de 1882. Este divorcio entre nacionalismo y liberalismo se expresa en la clara defensa del Estado multinacional o plurinacional como la mejor manera de salvaguardar la libertad (NúÑEZ, 1994), posición que lo lleva a hacer una crítica a STUART MiLl quien en sus Considerations on Representative Governm fent había expresado: "It is in general a necessary condition of free institutions, that the boundaries of governments should coincide in the main with those of nationalities" (citado por ACTON, 1955, p. 156). ACTON, al contrario, opinaba que la diversidad era una barrera importante para evitar la intrusión del gobierno en esferas más allá de lo político y que:

The co-existence of several nations under the same States is a test, as well as the best security of its freedom. It is also one of the chief instruments of civilization. [...] The combination of different nations in one State is as necessary a condition of civilized life as the combination of men in society (1955, p. 160).

ACTON establecerá más adelante una analogía entre pluralismo ideológico y pluralismo cultural: la ciudadanía puede comprender diversas nacionalidades de la misma manera que abarca diversas iglesias sin menoscabar el derecho personal y la libertad de conciencia ${ }^{11}$.

11 Específicamente sobre este tema, KYMLICKA, uno de los especialistas en el debate de la multiculturalidad, opina que sin embargo "la analogía entre religión y cultura es engañosa", porque para un Estado es completamente posible "no tener una Iglesia establecida. Pero no puede abstenerse de dar al menos parcial institucionalización de una cultura cuando decide qué lengua ha de ser usada en la enseñanza pública o en la provisión de los servicios estatales": WILL KyMLICKA ("The sources of nationalism”, en The morality of nationalism, McKiм y MСMАНAM, 
Ya casi al final de su texto AстоN escribe algo que resume su pensamiento y su concepción sobre la nación y el nacionalismo: "The greatest adversary of the Rights of nationality is the modern theory of nationality. By making the State and the nation commensurate with each other in theory, it reduces practically to a subject condition all other nationalities that may be within the boundary" (1955, p. 168). En su texto queda clara su posición y concepción: defiende a las naciones -que aquí son coincidentes con la nacionalidad-, pero condena el "principio de la nacionalidad", y con este al nacionalismo como base del Estado ${ }^{12}$.

El segundo momento importante de parte del liberalismo sobre el tema -quizás el más relevante por su perdurabilidad y trascendencia- lo desarrolla ERnest Renan, quien logra una síntesis en la conferencia dictada en la Sorbona el 11 de marzo de 1882. La conferencia, titulada "Qu'est-ce qu'une nation?", ha quedado como un referente clásico y lectura obligada dentro de los estudiosos de nación y nacionalismo hasta hoy en día. La conferencia fue dictada en el contexto específico de la crisis política y emocional francesa ante la pérdida de Alsacia y Lorena en la Guerra Franco-Prusiana en 1871, y fue concebida para enfrentar la línea de argumentación de HEINRICH voN Treitschke $(1903 \text {, v. 4) })^{13}$, quien desde Prusia ${ }^{14}$ justificaba plenamente la anexión de las dos regiones con criterios etnolingüísticos e históricos y se situaba del lado del militarismo prusiano y de Bismarck en su tarea. Es en este contexto en el que adquiere significado político y filosófico ${ }^{15}$ la voluntad de los habitantes de Alsacia para RENAN.

comps., Oxford University Press, 1997, p. 58), citado en Cerezo Galán (2004, p. 130). El liberalismo clásico, dirá CHARLES TAYLOR, es ciego a la diferencia. Sobre el doble liberalismo, el clásico republicano de HABERMAS y RAWLS, y el diferencial de los derechos complementarios de TAYLOR y KyMlicka, cfr. Ciudadanía, nacionalismo y derechos humanos (RUBIo, Rosales y Toscano, 2000).

12 Acosta SÁNCHEz (1992, p. 116) hace una crítica a Lord ACTON cuando escribe que este "se dirige contra el nacionalismo de las naciones sin Estado, idealizando el de las naciones con Estado, mucho más poderoso; el nacionalismo solo es 'criminal' en su fase reivindicativa". De otra parte, la defensa de Lord AстоN de la forma inglesa, en donde convergen diversas nacionalidades, hace que el texto haya sido también considerado como una justificación del imperialismo inglés de su tiempo.

13 La historiografía nacionalista encuentra en este historiador su más claro representante. Será desde sus seminarios en Berlin que "the future elites of Whilhelmine Germany were indoctrinated with teutomains, imperialist and anti-Semitic ideas... Racial overtones intermingled with anglophove and antisocialist, anti-democratic sentiments to make Treitsche the most effective apologist of the Wilhelmine period": BERGER (1997). Cfr. también SCHLEIER (1965).

14 Renan era un gran admirador de Alemania y de la cultura alemana, y consideraba que estas eran víctimas del militarismo prusiano.

15 Una excelente lectura de esta conferencia desde la filosofía y que reclama el humanismo de Renan y le quita peso a la coyuntura histórica y política se encuentra en De Mingo Rodríguez (2011). 
Es importante resaltar que estamos ante un autor que, no solo en lo que respecta a su concepción de nación, tuvo diferentes posturas durante su vida política ${ }^{16}$. La concepción de nación de RENAN antes de la derrota de Francia en Sedán y de la Comuna de París en 1871 descansaba sobre el principio dinástico. Será específicamente el contexto político lo que lo llevará a defender los intereses nacionales de Francia y con esto a adoptar un pensamiento menos conservador.

Su cosmovisión se la ha ubicado entre un liberalismo conservador y un pensamiento reaccionario: de defensor de la monarquía y de la idea de un principio dinástico, dará paso, después de la experiencia de la derrota y de la Comuna de París, a la defensa de una monarquía constitucional y conservadora -a la que no debe poner obstáculos el espíritu republicano francés-, pero no de una monarquía parlamentaria. Aquella monarquía constitucional le parecía ser el remedio para los excesos que traían, por un lado, el principio dinástico, y, por el otro, el principio democrático (estudio preliminar de BLAS Guerrero, en RenAN, 1987).

Renan es defensor en muchos de sus textos de la más conservadora de las lecturas de la nación: una de ellas fue considerarla como encarnación de una voluntad colectiva a través del concurso de un colegio de notables, representantes de las distintas aristocracias sociales; en su obra expone otras lecturas sobre la nación como resultado de la voluntad popular, y a veces se aproxima a los planteamientos alemanes de los elementos culturales en la base de nación (estudio preliminar de Blas Guerrero, en Renan, 1987).

En una de sus cartas a STRAuss dice, refiriéndose al principio de nacionalidades: "Está claro que, desde que se rechaza el principio de legitimidad dinástica, no hay más que el derecho de nacionalidades para dar una base a las delimitaciones territoriales de los Estados, es decir, de grupos naturales delimitados por la raza, la historia y la voluntad de los pueblos" ${ }^{17}$. Es empero con el tiempo que la concepción de Renan llegará a una noción diferente de la nación teniendo presente, además, el continuo mestizaje de razas y lenguas que existen dentro de las diferentes naciones ${ }^{18}$. $\mathrm{Al}$ mismo tiempo que esto

16 El mismo Renan escribiría en sus textos autobiográficos: "J'étais prédestiné à être ce que je suis, un romantique protestant contre le romantisme, un utopiste prêchant en politique le terre à terre, un idéaliste se donnant inutilement beaucoup de mal pour paraitre bourgeois, un tissu de contradictions, rappelant l'hircocerf de la scolastique, qui avait deux natures": RENAN (1992, p. 6).

17 1 $1^{\text {ere }}$ lettre à Strauss, en Renan (1992, p. 120) (trad. nuestra). Las Cartas a David Friedrich STRAuss (1808-1874), teólogo alemán, son escritas entre 1870, poco antes de comenzar la guerra francoprusiana, y 1874. Existe una versión alemana de las cartas de STRAuss a RENAN: STRAuss (2010).

18 En la 9. ${ }^{\text {a }}$ carta a STRAUSS, RENAN sostiene que las diferentes mezclas que se han dado en Alsacia como país germánico, pero antes como país celta y así hacia atrás, darían lugar a guerras sin fin: cfr. RENAN (1992, p. 155). 
ocurre, su principio de nacionalidades va a tener, y de manera creciente, la voluntad popular como sustrato.

Su conferencia sobre qué es una nación es de una claridad sorprendente, y ello a pesar de que él mismo ya en su primera frase señala que se propone analizar una "idea, clara en apariencia" pero que se puede prestar a los malentendidos más peligrosos.

Esta conferencia comienza por definir la nación a través de lo que no puede determinarla: ni la lengua, ni la raza como fundamentos naturales lo pueden hacer; ni una dinastía, ni el grupo de provincias que la componen: Estados Unidos y Suiza no tienen ninguna base dinástica; ni la religión, pues según RenAn ha devenido en tema individual y es asunto de la conciencia de cada quien; tampoco la geografía con sus límites naturales, ni la comunidad de intereses.

La nación, escribirá en la tercera parte de su conferencia, es "un alma, un principio espiritual". Más que las fronteras estratégicas o las aduanas comunes, el "haber sufrido juntos" es más decisivo para la comprensión de lo que es una nación. El olvido y el error histórico son parte esencial y por ello dirá que el progreso de los estudios históricos se convierte en un peligro para la nacionalidad. Una nación no tiene para RENAN -y aquí le habla directamente a Alemania- el derecho de decirle a una provincia "me perteneces"; las provincias son los habitantes, y si hubiese que consultar a alguien, es a ellos a quien habría que dirigirse. Así, una nación es un espíritu, "una familia espiritual, resultado del pasado, de los recuerdos, de sacrificio [...] no hablar la misma lengua o pertenecer al mismo grupo etnográfico; es el haber hecho grandes cosas juntos y querer todavía hacerlas en el futuro" (RenAn, 1987, p. 131, Prólogo a Discursos y conferencias). Las naciones no serán por ello cosas eternas y, así como comienzan, también pueden ser reemplazadas. Aunque Renan sostenía que una confederación europea las reemplazaría probablemente, entendía no obstante que, para el siglo en el que él vivía, la existencia de las naciones era la garantía de la libertad, porque de no existir ella, se impondría "una sola ley y un solo maestro".

De los dos textos específicos del liberalismo sobre la nacionalidad y la nación es sin duda el de RENAN el que tuvo y sigue teniendo un sinnúmero de lecturas, análisis y exégesis, y es este texto el que sigue siendo un punto de referencia alrededor de la concepción política y "subjetiva" de nación, concepción que se ha proyectado hasta hoy, de una parte, en uno de los ejes centrales del debate contemporáneo, a saber, el debate entre los "subjetivistas" y los "objetivistas" 19 , y, de otra, en los debates dentro del liberalismo alrededor del multiculturalismo. 


\section{B. El marxismo: FRIEDRICH ENGELS y KARL MARX}

La otra reflexión fuerte en el siglo XIX sobre la nación o sobre los problemas alrededor del principio de nacionalidades se hizo desde el marxismo. De los movimientos comunista, socialista y anarquista del siglo XIX y dentro de lo que podría llamarse la izquierda, no existe un texto específico sobre la cuestión de la nación o los nacionalismos, ni un autor que haya trabajado un tema específico acerca de estos problemas; de hecho, tanto para los anarquistas como para los blanquistas o bakunistas y para muchos de los comunistas y socialistas, los asuntos de la independencia nacional desviaban la atención de los verdaderos problemas de la clase trabajadora, y no veían la importancia de la cuestión nacional para el movimiento internacionalista de los trabajadores. Sin embargo hay una infinidad de textos que desde el marxismo se ocupan en profundidad de lo que se llamaría el "problema nacional" y que tienen que ver en gran parte con los debates al interior de la Primera Internacional (1864-1876), pero sobre todo de la Segunda (1889-1914) ${ }^{20}$.

Aquí nos limitaremos a exponer sintéticamente algunas de las posiciones que sobre la cuestión nacional se encuentran en los textos de MARX y ENGELS, por considerar que, dentro de todo aquello que puede ser atribuido a la izquierda europea del siglo XIX, son ellos quienes se ocupan del problema con más atención desde el punto de vista teórico, quienes ven su importancia dentro del movimiento obrero y quienes tendrán mayor incidencia en los movimientos nacionalistas de la segunda mitad de ese siglo en Europa, y luego en los movimientos de independencia nacional del siglo xx en los demás continentes.

Hay que advertir que, como para muchos autores de su tiempo, en los textos de MARX y Engels la palabra "nación" se encuentra en un mismo escrito utilizada también como nacionalidad, pueblo, Estado, patria, país, palabras que son usadas indistintamente por cuestiones meramente estilísticas en aras de evitar repeticiones. Hacer por ello un estudio detallado de la manera en que se concibe a la nación en los diferentes textos y acepciones sería un trabajo arduo que va más allá de los objetivos del presente artículo, pero que, además, no llevaría a ninguna parte puesto que lo fundamental no son las diversas denominaciones usadas en el tiempo sino el problema político y teórico avizorado que está en su base. No obstante, queremos presentar un par de elemento ${ }^{21}$ para delimitar una cierta comprensión de la nación dentro de la concepción materialista de la historia que establece algunas diferencias tanto sobre la manera en que entienden la nación los nacionalistas alemanes como sobre las concepciones de la burguesía liberal de su tiempo.

20 Para todo el debate al interior de la Primera y la Segunda Internacional cfr. el excelente trabajo de ROSENBERG (1988). Existe traducción al castellano.

21 Véase BARros (1985). 
Dentro de esta concepción, la nación moderna es creada por la acción del modo de producción capitalista, disolviendo y fusionando las viejas y distintas nacionalidades. "La burguesía va superando cada vez más el fraccionamiento de los medios de producción, de la propiedad y de la población [...] Provincias independientes que casi formaban solamente una alianza [...] se aglutinan para formar una nación, un gobierno, una ley, un interés nacional de clase, una línea aduanera" (MARx y ENGELS, 1988, pp. 283-284). Será precisamente la burguesía quien "fabrique" la nación moderna y quien, después de los cambios radicales que se dieron a finales del siglo xviII, se ponga a la cabeza de la misma; esa nueva categoría abstracta que será patrimonio de todos y en la que participarán también las clases no dominantes. Del mismo modo será dentro de este proceso que la gran industria cree a la clase en la que toda nacionalidad quedaría destruida: el proletariado. Si, como escribe MARX en el "Manifiesto del Partido Comunista" (1948), los particularismos nacionales desaparecerán con el mismo desarrollo de la burguesía, el mercado mundial y la producción industrial, se puede comprender que la nación moderna sea entonces algo pasajero destinado a evanescerse y que, bajo esta compresión, se insista en una defensa constante del internacionalismo. Ello sin embargo no significa que la nación moderna no sea para las clases oprimidas, y entre ellas el proletariado, un marco de lucha por la hegemonía y por un modelo de nación que no sea meramente abstracto y que, al contrario, ofrezca iguales derechos no solo en las leyes. En el "Manifiesto del Partido Comunista"22 escriben MARX y ENGELS:

A los comunistas les echan en cara, asimismo, que pretenden suprimir la patria, la nacionalidad. Los obreros no tienen patria. No se les puede quitar lo que no tienen. El proletariado, para poder conquistar el poder político, necesita elevarse a clase nacional, constituirse él mismo en nación, aunque no, ni mucho menos, en el sentir de la burguesía (MARX y Engels, 1988, p. 294).

Más allá de esta comprensión de la nación moderna y su directa correspondencia con la clase trabajadora que vendría a imponer una nueva dinámica en la sociedad y a derrumbar a la nación abstracta de la clase dominante con su igualdad solo formal y legal, MARx y ENGELS se ocuparían a profundidad del problema. Efectivamente se ha dicho y sostenido con mucha razón que los problemas de la nación y el nacionalismo no fueron nunca prioridad ni tampoco preocupación central de la teoría marxiana, de tal forma que esta hubiese realizado un tratamiento teórico específico y sistemático de estas

22 El Manifiesto es el texto programático de la Liga Comunista creada antes de su publicación en 1848; la liga sería un precedente importante de lo que después fueron la Primera Internacional (1864-1874) y la Segunda Internacional (1889-1894). 
cuestiones por separado ${ }^{23}$. Sin embargo, siendo MARX y ENGELS dos personalidades políticas y teóricas inmersas en su tiempo, reaccionarían a los desafíos del momento alrededor de lo que se entenderá dentro de esta corriente teórica y política como "la cuestión nacional" (MARX y Engels, 1979).

Es notorio que los problemas nacionales fueron un tema de preocupación constante, algo que se refleja en un sinnúmero de textos, cartas, declaraciones, conferencias y artículos que expresan unas posiciones y unos lugares definidos que constituyen los puntos de referencia del marxismo alrededor de esta problemática ${ }^{24}$. De hecho, algunos de los textos se escriben todavía en el marco del fracaso de la revolución de 1848 y con ello del fracaso en aproximarse a la unidad nacional para algunas de las "naciones históricas" -Alemania e Italia entre ellas. Pero además los debates al interior de la Primera Internacional sobre la cuestión polaca contra el anarquismo, el bakunismo y el blanquismo, y aún más los debates que se dieron en la Segunda Internacional, muestran que el tema fue de vital importancia: se presentaba a los socialistas marxistas de manera categórica sobre todo a través de los representantes irlandeses, polacos o checos que traían sus preocupaciones "nacionales" a los debates de la Internacional.

Relevante es también señalar que durante la vida política de MARX y ENGELS sus concepciones cambiarían, de tal forma que a la inicial "subordinación" de la cuestión nacional a la revolución proletaria le seguiría una comprensión mucho más dinámica e interdependiente entre los problemas nacionales y los problemas de la lucha de clases. Precisamente serán los movimientos en Polonia e Irlanda los que, por las razones que ahora veremos, captarán la atención de los dos autores, cuya reflexión contribuirá de forma esencial al cambio señalado. Esto se percibe de manera nítida en los importantes y abundantes textos de Engels sobre Polonia -de Engels se afirma que, con el tiempo, se convirtió en el "especialista" de los dos sobre esta materia (DeL PALACIO, 2009)- y también en los de MARX ${ }^{25}$, pero ante todo sobre Irlanda, que consideramos son los terminantes y los más contundentes para entender la comprensión que predominaría dentro del marxismo acerca de la cuestión nacional.

Ya desde el texto de Karl MARx para la inauguración de la Primera Internacional (1864-1874) se expresa el apoyo de la clase obrera a la causa de la independencia polaca ${ }^{26}$, posición que, desde sus inicios, no fue compartida

23 Véase Löwy, Haupt y Weil (1978); como también Del Palacio Martín (2009).

24 Parte de los escritos se encuentra en las declaraciones o materiales inconclusos de KARL MarX. Véanse MarX y Engels (1979) o MarX (1961).

25 MarX (1961).

26 De hecho, la Primera Internacional tuvo dentro de sus preocupaciones centrales la ayuda a los revolucionarios polacos, quienes en ese momento formaban parte del "Levantamiento de enero" (entre 1863 y 1864) organizado con la participación de los nobles y la aristocracia polaca, sobre todo contra la potencia rusa ocupante, levantamiento que pretendió revocar la división 
por muchos de los que conformaban las corrientes de izquierda; blanquistas, bakunistas y anarquistas negaban la existencia de la importancia para los internacionalistas de la "cuestión nacional". Esta dificultad desde sectores que conformaban la Primera Internacional tuvo que ver de cierta forma con la utilización por parte de NAPOLEÓN III, en su política imperial, del "principio de las nacionalidades". Al respecto, algunos de los textos de ENGELS apuntan a marcar una clara diferencia entre la defensa de la independencia polaca, que deberían hacer los internacionalistas, y el "principio de las nacionalidades". Polonia, escribirá, es habitada por gente de diferentes nacionalidades:

... like almost all other European countries. [...] Therefore, if people say that, to demand the restoration of Poland is to appeal to the principle of nationalities, they merely prove that they do not know what they are talking about, for the restoration of Poland means the re-establishment of a State composed of at least four different nationalities (ENGELs, 1866).

Y añade que con posterioridad al golpe de Estado de 1851, para el emperador LuIS NAPOLEón el principio de las nacionalidades se convirtió en el mejor nombre para llevar adelante su política exterior:

Every nationality to be the arbiter of its own fate - every detached fraction of any nationality to be allowed to annex itself to its great mother-country - what could be more liberal? Only, mark, there was not, now, any more question of nations, but of nationalities. [...] Here, then, we perceive the difference between the "principle of nationalities" and the old democratic and working-class tenet as to the right of the great European nations to separate and independent existence. The "principle of nationalities" leaves entirely untouched the great question of the right of national existence for the historic peoples of Europe; nay, if it touches it, it is merely to disturb it (ENGELS, 1866).

Así, algunos de los extractos de artículos periodísticos de ENGELs nos muestran en parte de qué se trataba la discusión en ese momento: el "principio de nacionalidades" era duramente criticado por ser un instrumento de las grandes potencias para impedir la tarea de las grandes naciones europeas de lograr tener una existencia nacional, un Estado nacional propio. MARX y ENGELS no defienden el "principio de nacionalidades" pues desde su perspectiva desviaría de la tarea más importante, que era la conformación de grandes Estados como entidades políticas que podían contener diferentes pequeñas

del territorio: dividida tres veces entre diferentes países en el siglo XVIII, Polonia desaparece del mapa en 1795. En 1832 es convertida en provincia de la Rusia zarista, lo que da inicio a un ciclo de revueltas e insurrecciones buscando su liberación e independencia. 
nacionalidades -nótese que aquí la nacionalidad tiene la connotación de comunidades culturales ${ }^{27}$.

Como se deduce de los textos, no todos los problemas nacionales se daban alrededor de las así denominadas grandes naciones europeas, pues "fue esta vinculación orgánica entre Estado y progreso humano [...] lo que serviría de base a ENGELS para formular su particular teoría de los "pueblos sin historia"" (Del Palacio, 2009, p. 10). En un párrafo de una carta a Bernstein de 1882, ENGELs se refiere a las pequeñas naciones eslavas como fuerzas que están con la reacción contempladas dentro de una coyuntura específica e inmersas en la dinámica del contexto:

Again, I do not propose to go into the question of how the smaller Slav nations have come to look to the Tsar as their only liberator. Let it suffice that they do so; we cannot alter the fact and it will rest at that until Tsarism has been smashed; if there's a war, all these interesting little nations will be on the side of Tsarism, the enemy of all bourgeois progress in the West. So long as this remains the case, I can take no interest in their immediate liberation here and now; they are as much our declared enemies as their ally and patron, the Tsar (ENGELs, 1882a).

De esta forma se va decantando uno de los postulados de la posición marxista alrededor de los movimientos nacionalistas: se los apoyó en la medida en que en su momento estos significaron movimientos que provocaron rupturas con el antiguo régimen. En esta lógica las luchas de las pequeñas naciones eslavas al momento del análisis que hace ENGELs fortalecían el zarismo, y, tanto como el zarismo, son declaradas como enemigas del progreso en Europa. En esta misma lógica se da el apoyo a Polonia en 1863, pues la lucha de los polacos por la unidad nacional cuestionaba la división de Polonia entre las tres grandes potencias -Rusia, Prusia y Austria-: la independencia polaca significaba necesariamente el rompimiento de este vínculo y el debilitamiento de estas tres potencias militaristas, sobre todo del zarismo ruso, "reserva reaccionaria de Europa", lo que a su vez impulsaría la emancipación de los pueblos europeos frente a los viejos regímenes:

So long as Poland is partitioned and subjugated, therefore, neither a strong socialist party can develop in the country itself, nor can there arise real international intercourse between the proletarian parties in Germany, etc. with other than émigré Poles. Every Polish peasant or worker who wakes up from the general gloom and participates in the common interest, encounters first the fact of national

27 ENGELs (1866) sostiene: "There is no country in Europe where there are not different nationalities under the same government [...]. Moreover, no state boundary coincides with the natural boundary of nationality, that of language". 
subjugation. This fact is in his way everywhere as the first barrier. To remove it is the basic condition of every healthy and free development (ENGELS, 1882b).

Sin embargo, será Irlanda quien ocupe la mayor atención de los dos autores -sobre todo de MARX-, país que permite ver de manera nítida la comprensión por parte del marxismo del problema nacional en la segunda mitad del siglo XIX, su relación con la lucha de clases y con el proletariado. MARX mismo promueve con insistencia el apoyo de la Internacional a la lucha de liberación de Irlanda. Este apoyo y la propaganda a favor de la Comuna de París para ese momento se convertirán, según ReNATO LEVRERo, en "la mayor contribución que MARX brindó al movimiento proletario de su época" (estudio preliminar, MarX y Engels, 1979).

Es solo a partir de $1867^{[28]}$ que la dialéctica entre la situación de Irlanda como "país colonia" y la revolución de los trabajadores en Inglaterra se resuelve defendiendo la posición de que la independencia nacional de Irlanda es la conditio sine qua non de la emancipación social del proletariado inglés. Se invierten de esta forma los términos que antaño partieran de que la independencia de Irlanda sería resultado de la revolución en Inglaterra. Este cambio en sus posiciones tendrá que ver con un intensivo estudio de parte de los dos autores sobre el colonialismo y el nivel de la crisis en los países capitalistas, en aras de percibir la madurez o la posibilidad de una revolución socialista.

Todavía en 1847 MARX decía en su "Discurso sobre el partido cartista, Alemania y Polonia" que para derrotar a la vieja sociedad ellos debían abatir a su enemigo interno y no formular "utopías sobre la liberación de las naciones" (MARX y ENGELs, 1979).

Pero ya en una carta a ENGEls de diciembre de 1869 escribía MARX:

The way I shall express the matter next Tuesday is: that, quite apart from all 'international' and 'humane' phrases about Justice for Ireland it is in the direct and absolute interests of the English working class to get rid of their present connection with Ireland. I am fully convinced of this, for reasons that, in part, I cannot tell the English workers themselves. For a long time I believed it would be possible to overthrow the Irish regime by English working class ascendancy. I always took this viewpoint in the New-York Tribune. Deeper study has now convinced me of the opposite (MARX, 1869).

En la relación entre la potencia colonial y el país colonia, la dominación no solo se expresaba en términos de riqueza y miseria, sino que esta relación de explotación de las colonias (en este caso de Irlanda ${ }^{29}$, pero también se

28 En 1867 fueron procesados, condenados a muerte y ejecutados tres dirigentes fenianos. En la Internacional, MARX pone la cuestión irlandesa en el orden del día.

29 Sobre esta relación colonizador-colonizado entre Inglaterra e Irlanda, MARX escribía en 
referirá a India y China) les permitía a las clases dominantes inglesas poder conceder a su vez mayor democracia en Inglaterra y así poder mantenerse mediante el consenso logrado; de esa forma, MARX llegaba a la conclusión de que la lucha por la liberación nacional de Irlanda no solo significaba acabar con el yugo del dominio económico inglés, sino que minaba la estabilidad política y social de la burguesía en la sociedad inglesa, lo que era importante para el proletariado inglés.

En carta a Ludwig Kugelmann de noviembre de 1869 reafirmaba Marx:

Cada día estoy más convencido -y solo es necesario inculcarle esta convicción a la clase obrera inglesa- de que ella nunca podrá hacer nada decisivo en Inglaterra hasta tanto no separe su política con respecto a Irlanda, en la forma más decidida, de la política de las clases dominantes, hasta tanto no solo haga causa común con los irlandeses y no tome incluso la iniciativa para suprimir la Unión establecida en 1801 y la sustituya por una relación federativa en pie de igualdad (MARX y Engels, 1979, p. 188).

Precisamente por la relevancia que tuvo Irlanda para MARX, estos textos permiten exponer de manera clara este otro postulado marxista, premisa central en relación con la cuestión nacional y que de manera sintética se puede expresar en que el proletariado de 'un país colonial que oprime a un país colonia' no puede liberarse a sí mismo. Los movimientos de liberación nacional del siglo xx se nutrirán en gran parte de estos postulados marxistas y serán la base de la concepción de Lenin -no de Stalin- desde 1905 sobre la cuestión nacional y la libre determinación de los pueblos.

III. DOS REFLEXIONES DESDE EL LIBERALISMO Y EL SOCIALISMO ANTES DEL FIN DEL LARGO SIGLO XIX: FRIEDRICH MEINECKE Y OTTO BAUER

\section{A. FRIEDRICK MEINECKE y los procesos de conformación de la nación en los Estados nacionales modernos}

Es solo a finales del siglo XIX, pero sobre todo a comienzos del xx, que la nación misma empieza a convertirse en objeto de análisis crítico, lo que se

un artículo publicado en 1855: "Ni el 'barrio irlandés' del parlamento ni el clero irlandés parecen darse cuenta de que, a sus espaldas, una revolución anglosajona está transformando radicalmente la sociedad irlandesa. Esta revolución consiste en la sustitución del sistema agrícola irlandés por el inglés, del sistema de pequeños arriendos por el de grandes arriendos, así como de los antiguos terratenientes por capitalistas modernos. [...] Los hechos principales que prepararon esta revolución son los siguientes: el año del hambre de 1847, que mató aproximadamente a un millón de irlandeses; la emigración hacia América y Australia, que se llevó otro millón y aún continúa llevándose a miles; la malograda insurrección de 1848, que destruyó los últimos restos de confianza en sí misma que tenía Irlanda; por último, la ley del parlamento, que entrega los bienes de la antigua nobleza irlandesa endeudada al martillo del ejecutor y del rematador, y la expulsa de la tierra, del mismo modo que la muerte por inanición expulsó a sus arrendatarios": MARX y Engels (1979, pp. 102-103). 
refleja en textos que tuvieron a la nación y al nacionalismo como tema específico de estudio y que muestran la realidad de estos problemas poco antes de la Primera Guerra Mundial.

Momento importante en la categorización de la comprensión de la nación es el trabajo de FrIEDRICK MeINECKE, liberal conservador, quizás el historiador alemán más importante de la primera mitad del siglo xx y alumno de WILHELM Dilthey. En la medida en que este se preguntó sobre cómo se había dado el devenir y la conformación de la construcción del Estado nacional alemán, dio un aporte sustancial a la comprensión general de la nación en Europa y a la conceptualización teórica del problema.

Su reflexión sobre esta construcción se encuentra plasmada en tres obras: Weltbürgertum und Nationalstaat (Cosmopolitismo y Estado Nacional) de 1907, en donde desarrolla su "filosofía del Estado", Idee und Staatsräson in der neueren Geschichte (Idea y razón de Estado en la historia reciente) de 1924 y Die Entstehung des Historismus (El nacimiento del historicismo) de 1936, con las cuales se puede decir que MeINECKE sintetiza como historiador su concepción del Estado.

Dentro de estos textos, sin embargo, el trabajo inicial de 1907, Weltbürgertum und Nationalstaat, es el que más nos interesa, porque es allí en donde desarrolla los conceptos de Kulturnation (nación-cultura) y Staatsnation (nación-Estado) que estarán en la base de los dos modelos del Estado moderno, y que para muchos será la contribución más importante de MeINECKE a la teoría del Estado -y de la nación- del siglo xx (Del ReAL, 2011).

Como bien se afirma, el aporte de MEINECKE a la discusión sobre lo nacional se presenta, en ese contexto y en ese momento, como "una disputa entre la visión liberal (renaniana) y la perspectiva conservadora (o germánica de base romántica-organicista) acerca de cómo construir la nación y el Estado nacional" (DEL REAL, 2011, p. 181), que, en últimas, apunta a la pregunta por la legitimidad o ilegitimidad de la incorporación de Alsacia y Lorena al territorio alemán. Así como en el caso de Renan que escribe su texto en el afán de minar la legitimidad de esta anexión, el berlinés MeInECKE va a legitimar esta anexión a través del proceso de la nation-building alrededor de la Kulturnation y la construcción del Estado nacional alemán.

Con respecto a lo que en últimas constituye una teoría del Estado, MEINECKE está en un momento en el que su teoría se encuentra junto a otras en Alemania, como son las del conservador CARL SCHMITT, pero también la del sociólogo Max Weber, la del liberal Hans Kelsen y las de los socialdemócratas Hermann Heller y Karl Renner/Otto Bauer -estas últimas difieren de la de MARX y Engels arriba expuestas.

Es precisamente en su libro Cosmopolitismo y Estado nacional (Weltbürgertum und Nationalstaat), escrito poco antes del inicio de la Primera Guerra Mundial, en el que desarrolla los fundamentos del Estado moderno. Él mismo 
comienza el primer capítulo sobre las generalidades de la nación, el Estado nacional y el cosmopolitismo, afirmando que quien quiera ocuparse de la historia del nacimiento de las ideas del Estado nacional debe tener una noción clara sobre la esencia de este y de la nación, y de la relación entre ambos conceptos (Meinecke, 1969). Desde ese punto de vista se ha reconocido que es el primer teórico en introducir de manera no secundaria el problema de la nación en la teoría del Estado (Del Real, 2011).

Como historiador intenta dar en este capítulo introductorio una orientación sumaria de lo que él afirma que "se puede diferenciar de los tipos y tendencias generales de la esencia de la nación y su devenir" (Meinecke, 1969). MeINECKE se pregunta sobre la nación no en sus "antiguos orígenes", si se quiere antropológicos, sino en un estadio más desarrollado, y en el significado de esta para la conformación del Estado moderno.

Aunque no hay un afán del autor por tomar a la nación como categoría por escudriñar, es precisamente el tratamiento del tema por medio de una tipificación de las naciones (y de los Estados nacionales) en Europa lo que le da vigencia hasta la actualidad. MeINECKE introduce, como lo señalamos, el problema de la nación -y de la nation-building - en el ámbito de la Teoría del Estado. Será precisamente en esta relación de la nación y el proceso de construcción de la nación con el Estado en donde él pondrá la diferencia: entre el Estado nacional moderno, basado en la Staatsnation (nación- Estado), y el Estado nacional moderno, que recibe una impronta cultural determinante desde la Kulturnation (nación-cultura). Con esto propone dos modelos centrales de Estado europeo que influyen en buena medida para que la forma de entender la nación y el nacionalismo "basculara definitivamente desde el ámbito de la Teoría de la Sociedad [...] hacia el ámbito de la Teoría del Estado y, asimismo, en que la doctrina sobre la nación se integrara desde ese momento (inicios del siglo xx) en el núcleo de las doctrinas que explican al Estado" (Del Real, 2007, p. 166).

Sintetizando podemos afirmar que, según MeINECKE, a una determinada vía para la construcción del Estado nacional corresponde una teoría específica de la nation building. La doctrina de la nación-Estado (Staatsnation) será la vía liberal, y la de la nación-cultura (Kulturnation) la vía étnica hacia la nación.

Desde su concepción, MeINECKE enuncia entonces dos grandes grupos en las naciones: las naciones-cultura (Kulturnation) y las naciones-Estado (Staatsnation). "En aquellas que preferiblemente tienen su base en una herencia cultural conjunta y compartida" (Kulturnation), una lengua común, una literatura y una religión conjunta, serán los bienes culturales los que permitan que se cree una nación-cultura. Las naciones-Estados son, por su parte, "aquellas que preferiblemente se basan en el poder asociador de una historia política conjunta y una constitución" (Staatsnation) (MeINEcke, 1969, p. 10) (trad. propia). La nación-cultura y la nación-Estado no pueden 
separarse nítidamente en sentido estricto: en la segunda pueden convivir diferentes miembros de naciones-cultura, como es el caso de Suiza, mientras que la primera puede, por ejemplo, crecer en diferentes naciones-Estado, como lo muestra Alemania.

Dice MEINECKE que se ha afirmado que la nación es lo que ella misma quiere ser: “L'existence d'une nation est un plébiscite de tous les jours" (RENAN). Sin embargo, sostiene que Alsacia, antes de 1870, aún queriendo pertenecer a la nación-Estado francesa y a su nación cultural, no ha perdido las huellas de la nación cultural alemana y las lleva consigo, y desde el punto de vista histórico pertenece a esta aun cuando no quiera pertenecer más a ella. Y no obstante esto, continúa el autor, no significa que niegue la verdad que se encuentra detrás de las palabras de RENAN, pues estas han nacido del espíritu de 1789 , de las ideas de la soberanía de la nación y de la nación-Estado que se da ella misma una constitución. MeINECKE escribe:

La voluntad hacia la nación ha tomado primero a la nación francesa y luego en el siglo XIX a la alemana y a la italiana y ha llevado a un rediseño de las grandes naciones-Estado en el continente. Pero a estos nuevos tiempos en los que prorrumpió de manera poderosa el deseo de ir hacia una nación-Estado, les antecedieron tiempos en los que esta voluntad nacional no se había despertado de manera tan consciente ni determinada, tiempos en los que no se puede hablar de una autodeterminación nacional en el sentido estricto de la palabra, tiempos en los que si tanto franceses como ingleses ya fueron una nación-Estado y al mismo tiempo una nación-cultura, por lo menos los alemanes e italianos eran una nación cultura. Y así nos vemos ante una cesura principal en el desarrollo de las grandes naciones nuevas, tanto de las naciones-Estado como de las naciones-cultura (1969, pp. 12-13) (trad. propia).

A partir de ello MEINECKE va a diferenciar, como se señaló, entre dos "tipos" de Estado moderno: aquel que tiene en su base la nación-Estado y el que tiene en su base la nación-cultura.

En relación con el primer tipo de Estado moderno, un elemento inicial importante para que una nación-Estado (Staatsnation) se desarrolle es una base territorial fija, los "Estados territoriales antiguos". En este Estado moderno las naciones-Estado se crean por medio del trabajo del mismo Estado, y la vida política conjunta por medio de un crecimiento lento y secular. Es ese sentimiento común político y duradero, eficaz hacia adentro como hacia fuera, "lo que convierte a los habitantes de un Estado en una nación-Estado y al Estado en un Estado nacional" (MeINECKE, 1969, p. 14) (trad. propia). Este Estado que se forja mediante la doctrina del Staatsnation va a ser identificado con los procesos que se dieron durante las revoluciones inglesas.

En el segundo tipo de Estado moderno la nación-cultura es la sustentadora del Estado nacional moderno. A diferencia del primero, fundamentalmente 
político, el Estado moderno en este caso será un producto de lo cultural, que expresa el espíritu de un pueblo (Volksgeist) particular y desde ese aspecto sustancial. El proceso de nacionalización y de construcción de lo nacional se da a partir de una sociedad específica:

Tenemos naciones-cultura y naciones-Estado; tenemos Estados nacionales en sentido político y Estados nacionales en sentido nacional cultural; hemos diferenciado dentro de los Estados nacionales en sentido político y además también entre la nación-Estado y las naciones-cultura, entre las que tienen una impronta antigua y las que tienen una impronta moderna. Al mismo tiempo hemos dejado además en claro siempre que en la realidad histórica estos diferentes tipos se mezclan. Pero sobre todo hemos contemplado hasta ahora a las naciones y a los Estados nacionales en sí y según sus propias cualidades inmanentes y sus objetivos. Esa manera de ver las cosas, sin embargo, no es suficiente todavía. Porque naciones y Estados nacionales no son -hemos indicado anteriormente- como tal solo ejemplares de determinado género, en parte conservados puramente o mezclados entre ellos, sino que portan, como toda formación histórica, también en alto grado un carácter singular (MEINECKE, 1969, pp. 20-21) (trad. propia).

MeINECKE dejará para el estudio de qué es la nación precisamente esta primera sistematización, que a pesar de su objetivo fundamental y concreto -explicar el devenir del Estado nacional en Alemania- permaneció como un sistema conceptual con capacidad de generalización y aplicación a los diferentes procesos en la conformación de los Estados nacionales europeos. Esta separación entre la nación-Estado y la nación-cultura es lo que reconocemos en el debate sobre la nación política y la nación cultural, subjetivismo vs. objetivismo en las discusiones de nación más contemporáneas, y que hemos expuesto al comienzo de este texto desde los procesos del nation-building francés y alemán como dos "tipos ideales".

\section{B. OtTo BAUER, el austromarxismo y el problema de las nacionalidades}

La reflexión quizás más completa y sistemática sobre la nación de comienzos de siglo la lleva adelante desde el austromarxismo ${ }^{30}$ el socialdemócrata

30 El austromarxismo se conformó como un grupo de intelectuales y políticos dentro de la socialdemocracia austriaca (algunos de los representantes más importantes son VICTOR AdLER, Karl Renner, Otto Bauer, Max Adler y Friedrich Adler), caracterizado por no tener una línea política común al interior de esta. Ha sido definido como una corriente marxista kantiana por "su interés en reexaminar los amplios fundamentos teóricos y epistemológicos del marxismo, que la crítica kantiana en particular había mostrado plagado de vacíos y ambigüedades" (LESzeK KollaKowsKi, 1982, citado por LóPEZ, 2011,p. 13). En su segundo prólogo, OtTo BAUER escribirá: "En mi época de estudiante, a cuyo término escribí La cuestión de las nacionalidades, estaba fascinado por la filosofía crítica de Immanuel KANT. Bajo la influencia de la teoría kantiana del conocimiento adquirí las concepciones sobre el método sociológico que dan fundamento a la 
austriaco ОтTO BAUER en su obra La cuestión de las nacionalidades y la socialdemocracia. Desde una de las corrientes de pensamiento fuertes de esa época, este libro se convertirá en un clásico. En el marco de este texto no interesa sintetizar las importantes diferencias con el marxismo de la socialdemocracia alemana ni con la socialdemocracia rusa -no solo alrededor de la cuestión de la nación-, sino ilustrar el marco histórico y los elementos esenciales de esta definición de uno de los más influyentes representantes de la socialdemocracia austriaca y su respuesta a la realidad de culturas múltiples en toda Europa central y oriental que allí se reflejaban, en especial en el imperio austrohúngaro. A pesar de la relevancia que los textos de KARL RENNER $^{31}$ tendrían en la obra de OTTO BAUER, vamos a enfocarnos solo en el texto arriba mencionado escrito por BAUER en 1906, por tanto cuando aún no había terminado la revolución de 1905 en Rusia y anterior a la Primera Guerra Mundial, y que tendría una segunda edición en 1924, luego de la dolorosa experiencia de la guerra.

Comprender la nación y la cuestión de las nacionalidades dentro del imperio austrohúngaro (monarquía imperial y real) forzó al marxismo austriaco a desarrollar una manera específica -además muy controvertible para las otras socialdemocracias- de intentar dar una solución rápida, tanto teórica como práctica, al problema que se planteaba con la crisis del Estado multinacional que era para ese momento la monarquía imperial y regia.

Los problemas de las minorías se hicieron realidad en este Estado, problema que ya a finales del siglo XIX se expresó de manera nítida dentro de la Segunda Internacional. Ello se traduciría al interior del Partido Democrático Social Obrero de Austria, después Partido Social Demócrata de Austria (sPö), en el hecho de que con su creación en el invierno de 1888-1889, este se debió estructurar en diferentes grupos nacionales, alemanes, checos, polacos, italianos, rutenos, eslavos del sur (SANDNER, 2002, p. 3), donde los tres primeros grupos fueron los determinantes en la política partidaria. El programa de Brünn de 1899 propone precisamente la conformación de una estructura federativa partidaria, con un comité unificado y una gran autonomía en las representaciones nacionales buscando, entre otras, contrarrestar la hegemonía alemana. Esto funcionó en la parte austriaca pero mucho menos en la parte húngara, en donde el partido era más débil y en donde de parte del gobierno

exposición de mi teoría de la nación [...] [E]n el transcurso de estudios posteriores [...] superé mis kantianas enfermedades infantiles y [...] revisé mis opiniones metodológicas" (BAUER, 1979, p. 7), lo que lo llevaría a concluir que con ello habría quizás cambiado el modo de exposición del texto pero no la teoría misma.

31 Como bien lo afirma SANDNER (2002), los textos de RENNER -que se había ocupado de la nación y el problema de las nacionalidades desde el punto de vista de la teoría del Estado jurídica- y de BAUER se complementan desde las premisas teóricas, pero desde el punto de vista práctico llegan a consecuencias bien diferentes. 
húngaro se practicaba una política bastante dura de homogeneización o "magiarización" intolerante hacia rumanos y eslovacos (LóPEZ, 2011).

El programa de querer mantener a toda costa la unidad nacional fue criticado tanto por la socialdemocracia alemana como por la rusa precisamente por haber reducido la cuestión de las nacionalidades a un problema político cultural de la superestructura, y porque al haber suprimido el derecho a la autodeterminación de los pueblos ${ }^{32}$, que había sido parte del programa de Neudörfl de $1874^{[33]}$, quedó del mismo lado que la monarquía en su defensa del Estado: en su búsqueda de soluciones a toda costa dentro del Estado unificado de la monarquía coadyuvó a la estabilización de esta y se convirtió así en el blanco de fuertes y justificadas críticas desde el movimiento socialista.

Durante el proceso de discusión preparatorio al programa de Brünn el debate había girado no ya sobre la posibilidad de un Estado multinacional (multinationale Staatswesen) sino sobre si se podría "salvar" este Estado (Staatswesen) (SANDNer, 2002). Hans Mommsen, reconocido historiador alemán, acierta cuando afirma que "la debilidad principal del programa se basó en que dejó de lado las interdependencias económicas y pretendió dar una solución a la cuestión de las nacionalidades austriacas a nivel local y a través del aislamiento de los asuntos nacionales de las contradicciones políticas del poder" (citado por SANDNER, 2002, p. 3) (trad. propia).

En el prólogo a la segunda edición de La cuestión de las nacionalidades y la socialdemocracia (1924) escribía OTTO BAUER:

Ya en el invierno de 1908-1909, a mí mismo me parecía probable que el proceso iría por un camino muy distinto a lo que había esperado en 1906: que el proceso conduciría a la guerra y, por obra de la guerra, a la revolución; la revolución pondría a la orden del día el viejo principio de las nacionalidades y haría saltar el viejo Estado de nacionalidades mucho antes de lo que yo había tenido por probable en 1906 [...]. Y luego, cuando en 1914 estalló la guerra a consecuencia de la cual, en 1917, se produjo efectivamente la segunda revolución rusa, me resultó indudable que en adelante el problema de las nacionalidades austrohúngaras podía ser resuelto tan solo por la disolución del imperio (1979, pp. 5-6).

En este mismo prólogo sostiene BAUER que el objetivo del libro siguió siendo para él legítimo y que no había perdido nada de su alcance inicial, que era comprender a las naciones modernas a través de la concepción marxista de la historia para llegar a una definición general de las naciones modernas de

32 En 1918 BAUER formuló y publicó el programa de las nacionalidades de la izquierda en donde se defendía y exigía vehementemente la libre determinación de los pueblos. Este cambio se dio después de haber sido prisionero de guerra en Rusia y con ello influenciado por la posición de Lenin.

33 El programa fue resultado de la primera iniciativa en la búsqueda de la creación de un programa socialdemócrata en el imperio austro-húngaro, posible solo hasta 1899. 
BAUER como comunidades de carácter nacidas de comunidades de destino. No está de más llamar la atención respecto de que, a diferencia del marxismo anterior, BAUER sí va a intentar definir la nación y construir una teoría alrededor de ella.

Estaba claro que el carácter nacional era algo que debía ser explicado. En el intento de BAUER por explicar la nación ${ }^{34}$ se diferencia tajantemente de la concepción del Volksgeist, del espíritu del pueblo, elemento fundamental en la definición de la nación del Romanticismo alemán; pensar que "las acciones y los destinos de una nación" pudieran ser entendidos como manifestación de este "espíritu del pueblo" era, según BAUER, espiritualismo nacional basado en una falsa manera de pensar: "National spirit cannot explain the community of national character, since itself is nothing but national character transformed into a metaphysical being, into a spectre" (BAUER, citado en Balakrishnan, 2012, p. 42).

El carácter nacional no tendrá así para BAUER una naturaleza sustancial, sino que será entendido como un precipitado de procesos históricos pasados modificado constantemente a través de los procesos históricos que se van dando. El carácter nacional no es una historia cuajada, $n i$ es inmodificable o constante ${ }^{35}$. Con ello se va a diferenciar categóricamente de aquellas concepciones genealógicas e inamovibles en la comprensión de la nación, predominantes durante gran parte del siglo XIX.

... la concepción materialista de la historia puede comprender a la nación como el producto jamás finiquitado de un proceso que se opera permanentemente y cuya última fuerza motriz son las condiciones de la lucha del ser humano con la naturaleza, las transformaciones de las fuerzas productivas humanas, las modificaciones de las relaciones de trabajo humano. Esta concepción hace de la nación lo histórico en nosotros (BAUER, 1979, pp. 130-131).

La tarea de derivar la peculiaridad nacional de la historia de la nación: eso, y nada más, significa mi definición de nación como comunidad de carácter nacida de una comunidad de destino (ibíd., p. 10).

El centro de gravedad de mi teoría de la nación no está en la definición de la nación, sino en la descripción de aquel proceso de integración de donde surgió la nación moderna (ibíd., p. 19).

34 El libro de Оtто BAUER, La cuestión de las nacionalidades y la socialdemocracia, es complejo, lleno de meandros y de largos ejemplos, lo que hace su lectura engorrosa. En el libro editado por BALAKRISHNAN (2012) se pueden encontrar los enunciados centrales en versión inglesa.

35 "[L]o que vincula a connacionales de la misma época es la comunidad del carácter; lo que vincula a los connacionales de diferentes épocas no es la homogeneidad del carácter, sino el hecho de que se suceden unos a otros, que actúan unos sobre otros y que los destinos de los anteriores determinan el carácter de los posteriores, de ninguna manera que las generaciones anteriores concuerden en carácter con las siguientes": BAUER (1979, p. 131). 
La teoría de la nación de este autor se derivaba por primera vez - de manera sistemática-del desarrollo económico, de las modificaciones de la estructura social y de la articulación en clases de la sociedad, conformado como un proceso de integración de donde surge, según él, la nación.

Adentrémonos un poco en lo que significan en su teoría la comunidad de carácter y la comunidad de destino, que son conceptos clave en su concepción. Habría que comenzar aclarando que la concepción de comunidad de este autor parte de IMMANUEL KANT para quien, como BAUER mismo lo expresa, la comunidad significa "recíproca interacción general”. La nación es una comunidad de destino, pero esta comunidad es vivencia común del mismo destino, no sometimiento a este. "Solo el destino vivido en recíproca interacción general, en permanente relación mutua, engendra la nación" (BAUER, 1979, p. 122). Se puede definir así la nación como la comunidad de carácter que no nace de una homogeneidad de destino, sino de una comunidad de destino.

Las condiciones en que los hombres producen su sustento vital y reparten el fruto de su trabajo determinan el destino de cada pueblo; sobre la base de determinado tipo de producción y reparto del sustento vital surge también determinada cultura espiritual [...]. La nación jamás es otra cosa que comunidad de destino. Pero la comunidad de destino tiene efecto, por un lado, a través de la transmisión hereditaria natural de las cualidades cultivadas por el destino común de la nación, y por el otro, mediante la transmisión de los bienes culturales determinados en su peculiaridad por el destino de la nación (BAUER, 1979, p. 43).

En la transformación de una sociedad agrícola en una industrial, es la modernización la que provoca una cultura nacional ${ }^{36}$. El capitalismo moderno ha logrado en la historia, y por vez primera, una cultura nacional para toda la población. Y lo ha hecho abriendo lo local, redistribuyendo a la población, provocando su desenraizamiento, en cuya tarea han sido decisivos elementos de la democracia como la educación primaria, el servicio militar obligatorio y el sufragio universal.

Podríamos resumir con LóPez $(2011)^{37}$ que OTTO BAUER construye su teoría de la nación en tres niveles: el primero alrededor de lo que llamó la "comunidad del lenguaje" (Sprachgemeinschaft), resultado fundamentalmente de la unificación económica que rompe el aislamiento característi-

36 Es interesante desde todo punto de vista leer, en su capítulo sobre lo que es una nación y sobre las incidencias del capitalismo moderno en la comunidad cultural nacional, elementos centrales explicativos que se encontrarán mucho después en un autor weberiano clásico de la nación y el nacionalismo como ERNEST GELLNER.

37 Para leer un texto que trate todas las implicaciones y contradicciones del concepto de nación en BAUER cfr. "La cuestión nacional según OTTO BAUER. Notas críticas en torno a un clásico”, en LóPEZ (2011). 
co de las comunidades agrícolas. "La comunidad lingüística nacional es para nosotros una de las formas de expresión de la comunidad de carácter nacional, una de las manifestaciones parciales de la comunidad cultural nacional, uno de los productos de la comunidad de destino nacional" (BAUER, 1979, p. 19).

Al segundo nivel se llega a través de la "comunidad cultural" (Kulturgemeinschaft), en donde juegan un papel importante las élites en su tarea de crear y diseminar una "alta cultura": "este proceso de integración de las épocas feudal y capitalista temprana solo pudo vincular en una comunidad cultural nacional a las clases dominantes" (BAUER, 1979, pp. 19-20). Los bienes materiales se convierten en cultura espiritual. Pero el desarrollo del capitalismo y su necesidad de explotación de amplios sectores impiden el desarrollo de la nación en una comunidad cultural nacional porque aquellos no pueden participar de ella:

Por ende, el hecho de la explotación también traba el devenir de la nación como comunidad cultural e impide la integración del obrero a la comunidad cultural nacional, y lo que vale para el obrero vale para el campesino explotado por el capital comprado y el capital hipotecario; vale para el artesano sojuzgado por el comerciante capitalista (BAUER, 1979, p. 104).

Con el desarrollo del capitalismo -esta cultura que impregna ya a la clase trabajadora a comienzos del siglo xx- se podrá construir la nación en su último nivel: realización de la comunidad nacional cultural por el socialismo, la comunidad política, el sentimiento político, la creencia en la nación como una "comunidad de destino" (Schicksalsgemeinschaft). "Recién el socialismo dará a la nación la plena autonomía y la verdadera autodeterminación, sustrayéndola a la eficacia de las fuerzas que no le son conscientes y se sustraen a su acción" (BAUER, 1979, p. 116).

Más allá de lo controvertida que haya sido su teoría de la nación, sobre todo desde las otras socialdemocracias y sus críticas al austromarxismo dentro del contexto político de la crisis del Estado y de la monarquía del imperio austrohúngaro para comienzos del siglo xx, hay ciertos aportes de este libro que fueron y han sido importantes: el despertar de las "naciones sin historia" -las naciones pequeñas de Europa central y oriental- descrito por él allí fue un acierto, y se puede considerar de gran actualidad teniendo en cuenta los desarrollos posteriores a las dos guerras mundiales y, después, a la caída del muro de Berlín. En este aspecto su rescate de la memoria histórica de las luchas del pasado, o el haber tenido en algún momento un Estado como memoria política -algo esencial que le permitió tanto a polacos como a checos un sustrato en el cual basar su nacionalismo- es importante. "In making these move he opened up a fruitful vein of investigation for future 
historians and pointed the way towards Hobsbawm's notion of the invention

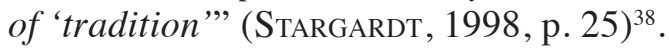

\section{REFLEXIONES FINALES}

Los autores que desde el liberalismo y el socialismo introdujimos -Acton, Renan, Engels, Marx, Meinecke y Bauer- escribieron desde diferentes miradas -filosofía, historia, derecho-, y todos ellos participaron desde sus concepciones y propuestas activamente en la vida política de su tiempo en el continente europeo. El nacionalismo precisamente se articuló como una alternativa al liberalismo y al socialismo y sería parte importante de la preparación para la Gran Guerra. De la Primera Guerra Mundial aparecerían, como resultado del derrumbe de los tres grandes imperios, un sinnúmero de nuevos Estados en Europa, acompañados de discursos de nación y legitimados con el principio de la libre determinación de los pueblos aclamados por Lenin y Wilson con sus diferentes connotaciones. Estas realidades se han vuelto a dar no solo en Europa oriental, ante el derrumbe de la Unión Soviética, sino en Europa occidental, con crecientes movimientos nacionalistas de diferentes colores en Irlanda, España, Reino Unido o Bélgica. Quizás precisamente por el hecho de haber sido testigos y participado desde sus concepciones en esta primera ola de nacionalismos europeos sea que estos legados continúan siendo útiles como reflexiones sobre una problemática que aún hoy es de actualidad.

Podríamos comenzar con la vigencia de los dos caminos de la nation building en la Europa del siglo XIX, concepciones que hasta hoy son controvertidas y discutidas. Mirar de cerca el debate sobre la naturaleza y orígenes de la nación (¿qué es la nación?, ¿cuándo es la nación?) nos lleva necesariamente a la concepción de nación política y nación cultural que se ha traducido en el debate entre los voluntaristas y los organicistas o entre los perennialistas y los modernistas ${ }^{39}$. Ciertamente el desarrollo de la nation building a partir de los elementos de la nación cultural ha dado pie a muchísimas controversias por ser considerada la base de los nacionalismos étnicos, sinónimo para muchos de los nacionalismos regresivos y xenófobos. Sin entrar en consideraciones sobre estas afirmaciones, pues no es este el lugar para ello, hay que reconocer que sigue siendo una constante el que los movimientos nacionalistas que no tienen en su base un Estado nacional recurran a elementos étnicos y culturales - aunque también a elementos políticos- en la búsqueda por legitimar y fundamentar su existencia como nación.

38 Para reflexionar sobre la proyección, hoy, de estos aportes alrededor de los amplios debates acerca de la multiculturalidad, sobre todo en algunos de los países industrializados, $\mathrm{cfr}$. LÓPEZ (2011, p. 17).

39 Véase Sмітн (1998), cap. 1. Hay versión castellana. 
En esta dualidad las recepciones actuales del liberalismo continúan rescatando la concepción política, el conocido plebiscito de todos los días del que habló Renan como la expresión de la voluntad política del individuo. Esta lectura del autor predomina a pesar del eclecticismo que alrededor de la nación respira su obra. "One consequence of this debate was that for the 'objectivist', nations and national sentiment could be found as far back as the tenth century, whereas for 'subjectivists' both were products of the eighteenth century" (SмIтH, 1998, p. 170). La sistematización de MEINECKE precisamente hace parte de la caracterización de las naciones europeas y con esta integra la doctrina sobre la nación a las doctrinas que explican el Estado en Europa. Su propuesta dual (nación-Estado, nación-cultura) del proceso de la nation building en el continente la tomará de manera crítica uno de los padres de la investigación sobre el nacionalismo a partir del periodo de entreguerras, HANS KoHN.

Más allá de esto, Lord Acton deja planteadas cuestiones centrales al interior del liberalismo, como el que la ciudadanía pueda comprender diversas nacionalidades, y se perciben los ecos de sus textos en el debate dentro del liberalismo, entre el clásico republicano de HABERMAS y RAWLS, y el diferencial de los derechos complementarios de TAYLOR y KYMLICKA, que se puede sintetizar en la relevancia del concepto de patriotismo constitucional como base de la comunidad política en HABERMAS, y en la frase de TAYLOR de que el liberalismo clásico es ciego a la diferencia ${ }^{40}$. El derecho de las minorías y el liberalismo sigue siendo un debate abierto $-\mathrm{y}$ con este la pregunta de qué es la nación.

Hay que señalar que dentro del multiculturalismo también se ha rescatado el texto de BAUER por ser visto como un precedente y antecedente importante en el intento de dar solución a la posibilidad de la convivencia de diferentes minorías nacionales dentro de un Estado multinacional ${ }^{41}$. Dentro del aporte de BAUER está igualmente la lectura que hace StARGARDT (1998) sobre la contribución del austromarxista a la 'invención de la tradición' -que después desarrolla entre otros HobsBawm; con ello se acerca a otro de los ejes del debate actual, a saber, la relación del pasado y del presente en la formación y el futuro de las naciones.

En relación a la libre determinación de los pueblos y el aporte del marxismo, a pesar de las lecturas que cuestionan el derecho a la secesión como parte de la libre determinación, es innegable que este derecho tiene vigencia política en la actualidad y la tendrá probablemente en el futuro. La concepción política del marxismo sobre la cuestión nacional influyó de manera importante en los movimientos de liberación nacional del siglo xx -desde Fanon hasta los

40 Véase TAYLOR (1993). Existe la versión inglesa, aunque sin el aporte de HaBERMAS.

41 Véase Nimni (1999). 
propios movimientos en Argelia o en Vietnam, para dar dos ejemplos-, y es parte del acervo teórico y de la concepción que manejan algunos partidos de izquierda hasta hoy allí en donde existen movimientos nacionalistas, no sin grandes deliberaciones al interior por la zona gris que se abre ante el cómo y el cuándo del apoyo político a un movimiento nacionalista-ejemplos de esto son precisamente Irlanda o Escocia en Reino Unido, o Cataluña en España-. Más allá se percibe la influencia del entendimiento de la cuestión nacional por MARX y ENGELS, en el siglo XIX, en teóricos marxistas importantes del siglo xx, como Tom Nairn (1977), Michael Hetscher (1995) o Terry Eagleton (1990), quienes se han ocupado de esta materia.

\section{REFERENCIAS}

Acosta SÁnchez, J. (1992). Los presupuestos teóricos del nacionalismo y el nuevo ciclo del fenómeno. Revista de Estudios Políticos (Nueva Época), 77, 95-138.

Acton, L. (1955). Essays on freedom and power. New York: The Noonday Press.

Anderson, P. (1985). El Estado Absolutista (7. a ed.). México: Siglo Xxi Editores.

Balakrishnan, G. (ed.) (2012). Mapping the nation. London/NewYork: Verso, New Left Review.

Barros, C. (1985). A base material e histórica da nación en Marx e Engels (137-207). Dende Galicia: Marx. Homenaxe a Marx no 1 centenario da súa morte. A Coruña: Edicions do Castro.

BAUER, O. (1979). La cuestión de las nacionalidades y la socialdemocracia. México: Siglo XXI.

Blas Guerrero, A. (1984). Nacionalismo e ideologías políticas contemporáneas. Madrid: Espasa-Calpe.

Blas Guerrero, A. (1994). Nacionalismo y naciones en Europa. Madrid: Alianza.

BERger, S. (1997). The search of normality. National Identity and Historical Consciousness in Germany since 1800. Oxford/New York: Berghahn Books

Cerezo Galán, P. (2004). Ética democrática, pluralismo y nacionalismo. Anales de la Real Academia de Ciencias Morales y Políticas, 81 (1), 113-146.

De Mingo Rodríguez, A. (2011). Nación, democracia y humanismo en Ernest Renan. Contrastes. Revista Internacional de Filosofía, vol. XvI, 109-128.

Del Palacio Martin, J. (2009). El PSOE y la “cuestión nacional”. Madrid: Universidad Autónoma de Madrid.

Del Real Alcalá, J. A. (2007). Estado cosmopolita y Estado nacional. Kant vs. Meinecke. Revista de la Facultad de Derecho de México, LVII (247), 165-203. 
Del Real Alcalá, J. A. (2011). La teoría del Estado de F. Meinecke: modelos de Estado moderno según las doctrinas "Staatsnation" y "Kulturnation". Revista de Estudios Políticos (nueva época), 154, 177-210.

Eagleton, T.; Jameson F. y Said, E. (1990). Nationalism, Colonialism and Literature. Minesota: University of Minesota.

Elias, N. (1997). Über den Prozess der Zivilisation. Soziogenetische und psychogenetische Untersuchungen. Frankfurt am Main: Suhrkamp.

Engels, F. (1866). What have the working classes to do with Poland? The Commonwealth, I, 159, 160, 165, en: [http://www.marxists.org/archive/marx/works/1866/03/24.htm].

Engels, F. (1882a). Engels to Eduard Bernstein In Zurich. Marx-Engels Correspondence 1882. Recuperado de: [https://marxists.anu.edu.au/archive/marx/works/1882/letters/82_02_22.htm].

Engels, F. (ed.) (1882b). Nationalism, Internationalism and the polish question. A letter to Karl Kautsky. Recuperado de: [http://www.marxists.org/archive/marx/works/1882/ letters/82_02_07.htm].

Fusi Aizpurúa, J. P. (2006). El nacionalismo en el siglo xx. Circunstancia, 9, año III.

FusI, J. P. (2003). La patria lejana. El nacionalismo en el siglo XX. Madrid: Santillana, Taurus.

Hetcher, M. (1995). Explainig nationalist violence. Nations and Nationalism, 1, 1, 53-68.

Hobsbawm, E. J. (1990). Nations and Nationalism since 1780. Programme, Myth, Reality. Cambridge: Cambridge University Press.

López, D. (2011). La cuestión nacional según Otto Bauer. Notas críticas en torno a un clásico. Estudios Sociales, Santa Fe, Argentina, 41, año XXI, 9-40.

Löwy, M., Haupt, G. y Weil, C. (1978). Los marxistas y la cuestión nacional. Barcelona: Fontamara.

Marx, K. (1869). Marx to Engels in Manchester. Marx - Engels Correspondence 1869. Recuperado de: [http://www.marxists.org/archive/marx/works/1866/03/24.htm].

MARX, K. (1961). Manuskripte über die polnische Frage (1863-1864) (Werner Conze Dieter Hertz-Eichenrode Edition). Amsterdam: Mouton \& Co.

Marx, K. y Engels, F. (1979). Imperio y Colonia. Escritos sobre Irlanda. México: Siglo XXI Editores.

Marx, K. y Engels, F. (1988). Los grandes fundamentos. México: Fondo de Cultura Económica.

MeinecKe, F. (1969). Weltbürgertum und Nationalstaat. München, Berlin: R. Oldenbourg Verlag.

NaIrn, T. (1975). The Break-up of Britain: Crisis and Neo-Nationalism. London: New Left Books. 
Nimni, E. (1999). Nationalist multiculturalism in late imperial Austria as a critique of contemporary liberalism: The case of Bauer and Renner. Journal of Political Ideologies, 4 (3), 289-314.

Núñez Florencio, R. (1994). ¿Liberalismo o Nacionalismo? Nueva Revista, 34.

Renan, E. (1987). ¿Qué es una nación? Cartas a Strauss. Madrid: Alianza Editorial.

Renan, E. (1992). Qu'est-ce qu'une nation? Et autres essais politiques. Paris: Pocket.

Rosenberg, A. (1988). Demokratie und Sozialismus. Frankfurt am Main: Athenäum.

Rubio, J.; Rosales, J. M. y Toscano, M. (2000). Ciudadanía, nacionalismo y derechos humanos. Madrid: Trotta.

SANDner, G. (2002). Austromarxismus und multikulturalismus. Kakanienrevisited, 1-12.

Schleier, H. (1965). Sybel und Treitschke. Antidemokratismus und Militarismus im historisch-politischen Denken großbourgeoiser Geschichtsideologen. Berlin.

Smith, A. D. (1998). Nationalism and Modernism. A critical Surrey of recent theories of nations and nationalism. London-NewYork: Routledge.

Stargardt, N. (1998). Beyond the liberal idea of the nation. En Cubbit, G. (ed.). Imagining nation. Manchester - New York: Manchester University Press, 22-38.

Strauss, D. F. (2010). Krieg und Friede, zwei Briefe an Ernst Renan. Navu Press.

Taylor, Ch. (1993) Multikulturalismus und die Politik der Anerkennung. Mit comentaren von Amy Gutmann (Hg.), Steven C. Rockefeller, Michael Walzer, Susan Wolf. Mit einem Beitrag von Jürgen Habermas. S. Ficher.

Tilly, CH. (1990). Coerción, capital y los Estados europeos, 990-1990. Madrid: Alianza Editorial.

TreitschKe, H. G. (1903). Historische und politische Aufsätze. Leipzig: Verlag von S. Hirzel. 